\title{
КАТЕГОРИАЛЬНЫЕ ПРОСТРАНСТВА В ПОСТАНОВКАХ И РЕШЕНИЯХ ПРОБЛЕМЫ СОЗНАНИЯ ${ }^{3}$
}

Акопов Г.В. (Самарский государственный сочиально-педагогический университет, Самара, Россия) akopovgท@gmail.com

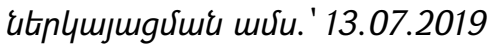

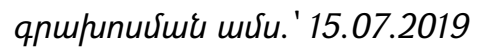

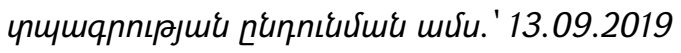

Существенное переосмысление и расширение терминологических средств определения сознания (qualia, subjectivity, access-consciousness, global workspace и др.), а также методологических оснований, подходов и концепций позволили сформировать новую область междисциплинарных исследований в англоязычных источниках («Наука сознания»). Культурноисторическая специфика развития научных знаний в различных странах обусловила определенные различия в терминологическом оформлении проблемы сознания. Категории как основополагающие понятия, в совокупности со взаимосвязанными понятиями и терминами, предопределяют постановку, подходы и концептуальные решения проблемы сознания. В этом контексте можно говорить о различных категориальных «пространствах» проблемы сознания. Категориальные пространства различных теорий сознания могут быть инструментом не только анализа целостности той или иной концепции, но и сравнительных, а также кросскультурных исследований.

Ключевые слова: сознание, проблемы сознания, различные подходы, концепции; социокультурная специфика; термин, понятие, категория; категориальные пространства.

Проблема сознания, более века назад, усилиями В. Вундта, У. Джеймса, В.М. Бехтерева и др. перешедшая в лоно науки из религиозных и философрских учений, вновь оказалась в фокусе внимания обновлённой философии и технически перевооружённой науки о мозге. Наметившееся, вместе с «наступлением» квантовой фризики, сближение границ познания материального (физического) и ментального (психического) миров [29 и др.; 15, 16 и др.], сегодня воодушевляет (или беспокоит) возможностью «прорыва» границы. Последовательная редукция дилеммы: Человек и Дух (мировоззрение) в формах связи души и тела, мозга и

3 Исследование выполнено при финансовой поддержке РффИ в рамках научного проекта №19-013-00816 «Многомерность сознания как проблема современной психологии: типологизация подходов и конструирование системы категориальных пространств» 
сознания, оставляет за пределами исследовательского внимания социальность как главное условие существования сознания.

Новый всплеск интереса и стремительный рост количества работ по проблематике сознания с конца 60-х гг. XX в. в психологической науке США и Европы не «симметричен» российским исследованиям в этой области. В российской психологии сопоставимого периода тема сознания была методологически и теоретически вполне проработана в диалектико-материалистической системе научных понятий и не нуждалась в переосмыслении и концептуальном оформлении, включая неизменно трудную психофизическую (психофизиологическую) проблему в её приложении к сознанию. Поэтому определяющие сознание понятия «феноменальность», «интенциональность», «квалиа» и др., вызвав определённый интерес у российских аналитических философов, не получили соответствующего резонанса в российской психологии. Выскользающее из русской фоносемантики слово квалиа (qualia), обозначающее, как ясно из приводимых примеров, вполне эквивалентно понятию сенсорного сознания [30], становится символом неразрешимой загадки сознания [33]. Неясность состоит в отсутствии ответов на следующие вопросы: 1) каким образом наши ощущения красного, кислого, громкого и т.д. осознаются; 2) для чего необходимо такое осознание (мысленный эксперимент ситуации «Зомби» доказывает, что можно обойтись без процессов сознания и осознания) [5; 6; 23 и др.]. С ответами на эти вопросы, приведёнными в теориях сознания (Л.С. Выготский, А.Н. Леонтьев и др.), можно спорить, но они, к сожалению, мало известны за пределами России.

Аналогичные вопросы закономерны в отношении визуального (перцептивного) сознания, когнитивного сознания, эмоционального (аффеективного) сознания и др. Как отмечает Т. Honderich, множество альтернативных терминов и словосочетаний, в первом приближении, определяют один и тот же класс феномена - «сознание» в его главном значении. Это, в частности: «experience», «qualia», "phenomenal», "subjective experience», "what it is like» и др. [30, с. 47]. Такое многообразие терминов, понятий и категорий, отнесённых к сознанию, не характерно для российских исследований в этой области, в отличие от все более расширяющегося исследовательского поля, обозначаемого «как Наука сознания", которая приобретает все более широкий междисциплинарный характер. Не затрагивая тесные взаимосвязи Науки сознания с Нейронаукой (нейрокогнитивные исследования), Дэвид Чалмерс наполняет конкретным содержанием взаимосвязь философии сознания и науки сознания: «Психология вместе с феноменологией составляют центральные аспекты ментального», - считает Чалмерс [23, с. 41]. Диффреренцируя смысловые определения феноменального сознания и психологического сознания по фрункциональному критерию причинно-следственных связей (каузальность) для случаев психологического сознания, Чалмерс, вместе с тем, устанавливает определённые связи между тем и другим сознанием по 
критерию такого проявления сознания как «осведомлённость». Так, в частности, в проявлениях психологического сознания может иметь место осведомлённость как связанная, так и не связанная с феноменальным сознанием в виде опыта соответствующего переживания [23, с. 46, 49].

Главное отличие феноменального сознания от психологического, согласно Чалмерсу, заключается в том, что для первого, пока, не получены ответы на два упоминавшихся вопроса: 1) Для чего сенсорный опыт сопровождается процессами сознания? 2) Каким образом осуществляются процессы сознания? Для явлений психологического сознания, как считает Чалмерс, ответы на эти вопросы либо уже получены в логике функционализма (каузальности), либо принципиально возможны, и в этом смысле всю проблему сознания можно разделить на трудную и относительно лёгкую части по соответствующим задачам [23, с. 54].

Функционализм и, в частности, его крайняя фрорма - прагматизм [36], со времён У. Джеймса существует как теоретическая платформа для тех или иных концепций психического (ментального) и сознательного. Особенностями концепции Чалмерса являются введённые им для решения проблемы сознания понятия «супервентность» и «дуалистический натурализм» [23]. В связи с таким решением проблемы сознания, как и решением, предложенным Джоном Сёрлом («биологический натурализм») [37], можно с уверенностью предположить, что их принятие российскими психологами может быть в значительной мере осложнено традиционным убеждением противоположности материального (природного) и идеального (ментального, сознательного). Однако, противопоставление феноменального и психологического, в частности, квалиа (qualia) и «доступа к сознанию» (access - consciousness) представляется нам не более обоснованным [23; 28 и др.]. Популярным аргументом неразрешимости трудной проблемы сознания стал приведённый Томасом Нагелем пример непостижимости человеком «субъективного опыта» летучей мыши в силу принципиальной разницы в устройстве сенсорных систем человека и летучей мыши [35]. Этот пример фрнкционально идентичных (ориентирующих в пространстве) сенсорных (психологических) систем с принципиально разными фризическими основами ассоциируется по контрасту с общей информационной основой человеческого сознания и возможностью искусственного интеллекта [9; 38].

Трудная проблема сознания определяет серьезный вызов не только для философии и психологии, но и для всей системы научных знаний, включая фризические науки, объясняющие фундаментальные основания всего мироздания. Новейшие решения трудной проблемы сознания, в одном из вариантов, связаны с комплексированием информационного и квантово-физического подходов, что определяет одно из новых направлений постановки и решения проблемы сознания [15; 16; см. также специальный выпуск журнала - Journal of Consciousness Studies (vol. 26, №1-2, 2019. Ed. Garrett Mindt)]. 
В 2013 г. заинтересованному русскоязычному читателю стал доступен осуществленный финским ученым А. Ревонсуо ${ }^{4}$ системный обзор филлософрских, психологических, нейробиологических исследований по проблеме сознания, выполненных до 2010 г. [18]. Автор определил жанр своей работы как «введение в проблему, нередко страдающую от глубоких и сложных фрилософских и эмпирических противоречий и значительной путаницы понятий [18, с. 19]. Этот обзор показал широкое терминологическое многообразие определений психических явлений, связанных с проблемой сознания.

Совокупность терминов, привлекаемых при построении той или иной теории, может обозначаться как «пространство» в случае выделения определенных терминов в качестве базовых (основополагающих). Будем называть такие термины категориями, а совокупность всех необходимых и достаточных терминов и понятий для оформления соответствующей теории - категориальным пространством этой теории сознания. Термины и понятия будем также «статусно» различать по критериям широкого словарного значения (термины) и более узкого, конкретно научного (та или иная научная область знаний) содержания.

В этом ряду мы также рассматриваем метафорические слова и словосочетания, достаточно широко, либо устойчиво встречающиеся в описаниях проблемы («поток», «светлое пятно», «просветление», «озарение» и др.). Статус понятия присваивается термину в связи с использованием в определенной отрасли знаний или научной дисциплине: философия, биология, психология, физиология, нейрология и др. Категории номинируются в привязке к определенной теории в рамках той или иной отрасли знаний. Так, к терминам, используемым в научных работах по проблеме сознания в англоязычной литературе, можно отнести слова: «brain», «mind», «body», «mental», "awareness», «consciousness», также встречающиеся в других областях знаний, но только последнее из перечисленных («consciousness») можно отнести к основополагающему понятию Науки сознания, в которой сегодня существует большое количество различных концепций сознания. В ней же (Наука сознания) можно выделить «видовые» понятия: «sensory consciousness», «visual awareness», и т.д.; операциональные понятия: "soft-report», «subjective reports», «sens of self», «нейронные корреляты сознания» и др. К категориям, в нашей трактовке, следует отнести основополагающие для той или иной теории сознания понятия, как, например, "global workspace» (теория Б. Баарса), «inner presence» (теория А. Ревонсуо), «reflexive consciousness» (теория М. Велманса) и др. Категории «глобального» характера, в отличие от частно-теоретических, определяют те или иные методологические принципы, подходы в решениях проблемы

4 Директор группы исследования сознания в Центре когнитивной нейронауки при Университете г. Турку, Финляндия; редактор журнала "Consciousness and Cognition» и др. 
сознания: «Phisicalism», «Reductionism», «Eliminativism», «Representationalism», «Dualistic naturalism» и др.

Построение терминологических, понятийных, категориальных словарей в современной Науке сознания в англоязычной и русскоязычной версиях, структурированных в соответствии с традиционной классификацией явлений сознания: процессы сознания (внимание, память и т.д.), состояния сознания, индивидуальные и личностные свойства, а также в логике, предложенной нами типологии проблем сознания [3], представляет актуальную задачу.

Конструирование соответствующих терминологических, понятийных и категориальных множеств, систематизированных по определённым характеристикам пространств того или иного типа, определит, на наш взгляд, глубину проработки проблемы, сознания и предлагаемых решений. Это могут быть строго «вложенные» друг в друга субпространства терминов - понятий - категорий, либо пересекающиеся в том или ином объеме рассматриваемых переменных, либо в той или иной степени изолированных. В качестве количественной меры близости (расстояние) пространств можно принять число совпадающих «элементов» [22, 24]. Другое направление исследований категориальных пространств проблемы сознания может быть связано с контент-анализом, либо дискурсивным анализом соответствующих совокупностей терминов - понятий - категорий.

Дифрференцируя междисциплинарные и унитарные (предмет изучения остаётся сугубо в рамках психологии) исследования сознания, мы, тем не менее, можем объединить термины, понятия и категории в едином фриксированном «пространстве». Конструируемый базис (основополагающие, т.е. необходимые и достаточные термины, понятия или категории) определяется в соответствии с типологическим статусом исследования по проблеме сознания [3].

Возвращаясь к «пяти ведущим идеям» в трактовке сознания [30], рассмотрим их с точки зрения культурно-исторической методологии [8; 12 и др.], одним из логических инструментов которой является социальная коммуникация. Коммуникация в широком плане может определяться через взаимодействие, и в этом случае можно говорить о фризической, химической, биологической и т.д. коммуникации (взаимодействии). В узком значении под коммуникацией подразумевается информационное взаимодействие, и тогда в рамках социальной коммуникации обнаруживают себя знаковая, символическая, метафорическая и другие языки коммуникации [2]. Социальная коммуникация не ограничивается такими видами коммуникации, как массовая, макро- и микро- групповая, межличностная, но включает также внутриличностную коммуникацию, которая, как показал Л.С. Выготский (см. также Morin), уже в раннем детском возрасте носит социальный характер [7, 34].

В этой логике, «квалиа» как осознаваемый опыт сенсорного и, возможно, перцептивного, когнитивного, афффективного и так далее порядка, может быть 
объяснён актуализацией внутренней коммуникации, каузальность которой (функция) имеет культурно исторические корни. Совместная деятельность человека, обеспечивающая выживание и развитие, невозможна без обмена действиями и афффективными «взаимооценками». Универсальной формой социального взаимодействия, очевидно, является информационная коммуникация. Средствами такой коммуникации могут быть телодвижения, зрительные образы в материализованных изображениях, звуковые сигналы, образы и знаки в их естественной, либо технической реализации, интонационная «речь» и др. [21].

Средства и формы коммуникации (внешняя - внутренняя, активная пассивная, ситуативная - отсроченная и др.), определяют множество языков сознания [10]. Актуализация того или иного языка социальной коммуникации определяет соответствующий тип сознания - телесное, образное, знаковое (словесное), речевое и др. Таким образом, определяя сознание в терминах «квалиа", мы выстраиваем сенсорно-перцептивное пространство сознания, которое, очевидно, очерчивает очень важную, но всё же только часть всего многообразия явлений сознания [13; 3].

Коммуникативность другой идеи о сути сознания - "What it's Like» [30] вполне очевидна как по формам внешней, так и внутренней коммуникации. Любопытно также отметить, что третья ведущая идея определения сознания (Subjectivity), совместно с двумя приведенными выше, по нашему мнению, образуют триаду, в которой такая категория сознания как "квалиа» выражает отнесенность внешних объектов к воспринимающему «Я»; другая категория сознания ("What it's Like») отнесенность посредством «Я» внешних объектов к внешним же объектам; третья категория (Subjectivity) - отнесенность самого «Я» к внешним объектам.

Две другие из упомянутых пяти [30] категорий («Phenomenality», "Intentionality») трудно или невозможно связать с социальной коммуникативностью. Однако, обращаясь к интенциональности как понятию, выражающему категорию сознания, следует отметить, что существуют серьезные возражения такому утверждению. Определенная логика анализа убеждает, что “Intentionality" нельзя использовать для объяснения сознания [32]. Следовательно, понятие интенциональности, предложенное еще Брентано в качестве основополагающей категории психики, нуждается в более основательной аргументации с точки зрения присвоения ей статуса категории, объясняющей явления сознания [32].

Понятие френоменальности существенно основано на феноменальных знаниях и френоменальных суждениях [26], что, очевидно, невозможно без процессов внешней или внутренней коммуникации. Однако трактовки этого понятия аналогичны определениям Kvalia, Subjectivity и What it's like [26].

В системе категорий, предложенной Д. Чалмерсом, френоменальному сознанию противопоставлено психологическое сознание, которое включает также все другие проявления сознания, которые можно трактовать в логике 
функционализма. Привлекая понятие супервентности, Чалмерс обосновывает концепцию дуального натурализма и в таком категориальном офрормлении предлагает теоретическое решение проблемы сознания.

В иной, инструментальной (измерительной) логике, используется полярность терминов в психосемантической концепции, предложенной В.Ф. Петренко, что делает возможным исследовать категориальные структуры реального индивидуального и общественного сознания [14]. Конструирование психосемантических пространств личности и социальных групп, основанное на субъективной оценке личностью тематически отобранных семантических шкал с последующей математической фракторизацией, кластеризацией и т.д. позволяет определять интересующие исследователя проекции сознания по различным аспектам жизнедеятельности человека. Таким образом, сознание в процессе исследовательского «зондирования» обретает хронотопическую многомерность и оценочную глубину [13].

К концу первой декады XXI в. в Российской психологии сформировалась достаточно представительная совокупность новых взаимодополнительных научных постановок и решений проблемы сознания [4; 5; 1; 17; 20 и др.], а также методологических реноваций самой проблемы $[5 ; 13 ; 3 ; 19 ; 11 ; 25$ и др.]. Установившийся русскоязычный терминологический аппарат проблемы сознания во многом значительно отличается от сопоставимого англоязычного. Построение категориальных пространств проблемы сознания в различных лингвистических версиях позволит также провести сравнительный анализ постановок и решений проблемы сознания в логике кросс-культурных исследований.

\section{Литература}

1. Агафонов А.Ю. Когнитивная психомеханика сознания. Самара, 2007.

2. Акопов Г.В. Психология сознания. Вопросы методологии, теории и прикладных исследований. М.: Изд-во «Институт психологии РАН», 2010.

3. Акопов Г.В. Типология проблем в новом познании сознания // Мир психологии. Научно-методический журнал. 2016. №2 (86). Апрель - июнь. С. 178-191.

4. Александров Ю.И. Эмоции и мораль // Методология и история психологии. 2008. Т. 3. С. 186-208.

5. Аллахвердов В.М. Методологическое путешествие по океану бессознательного к таинственному острову сознания. СПб.: Речь, 2003.

6. Аллахвердов В.М. Сознание как парадокс. СПб., 2000.

7. Выготский Л.С. Мышление и речь // Выготский Л.С. Собр. соч. В 6 т. М., 1982а. Т. 2. Проблемы общей психологии. С. 5-295.

8. Выготский Л.С. Проблема сознания // Собр. соч. В 6 т. М., 1982б. Т.1. Вопросы теории и истории психологии. С.156-167.

9. Дубровский Д.И. Сознание, мозг, искусственный интеллект: сборник статей. М., 2007. 
10. Зинченко В. П. Сознание и творческий акт / В.П. Зинченко. М.: Изд-во «Языки славянских культур», 2010.

11. Карпов А.В. Психология сознания: метасистемный подход. М.: РАО, 2011.

12. Коул М. Культурно-историческая психология: наука будущего. М.: «КогитоЦентр», Изд-во «Институт психологии РАН», 1997.

13. Петренко В.Ф. Многомерное сознание: психосемантическая парадигма. М.: Новый хронограф, 2010.

14. Петренко В.Ф. Основы психосемантики. 2-е изд., доп. СПб.: Питер, 2005.

15. Петренко В.Ф., Супрун А.П. Методологические пересечения психосемантики сознания и квантовой физики. 2-е изд., доп. М.; СПб.: Нестор-История, 2017.

16. Прыгин Г.С. Неклассическая психология: психология субъектной реальности. Монография / Г.С. Прыгин. Наб Челны: Изд-во НГПУ, 2018.

17. Райков В.Л. Объединенная теория сознания // Психология и её приложения. Ежегодник РПО. Т. 9. М., 2002. С. 67-89.

18. Ревонсуо А. Психология сознания / Пер. с англ. СПб.: Питер, 2013.

19. Сайко Э.В. Сознание в определении человека // Мир психологии. 2006. № 2. С. 3-11.

20. Субботский Е.В. Строящееся сознание. М., 2007.

21. Торопова А.В. Интонирующая природа сознания. М.: ООО Изд-во Ритм, 2013.

22. Цаленко, М.Ш., Шульгейфер, Е.Г. Основы теории категорий / М.Ш. Цаленко, Е.Г. Шульгейфер. М., 1974.

23. Чалмерс Д. Сознающий ум: В поисках фундаментальной теории. Пер. с англ. М.: УРСС; Книжный дом «ЛИБРОКОМ», 2013.

24. Шевелёв, Ю.П. Дискретная математика / Ю.П. Шевелёв / Учебное пособие. СПб.: Издательство «Лань», 2008.)

25. Akopov G.V. Typological approach to analysis of various consciousness research programs // $19^{\text {th }}$ Annual Meeting of the Association for the Scientific Study of

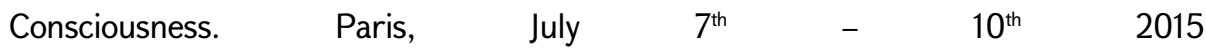
(http://www.theassc.org/files/assc/Book\%20of\%20Abstract.pdf ). P. 52.

26. Alter, T Phenomenal concepts // The Oxford companion to Consciousness. Edited by Tim Bayne, Axel Cleeremans, Patrik Wilken. 2009. OXFORD Univesity Press. Pp. 516-518.

27. Baars, B.J. (1988) A cognitive theory of consciousness. New York: Cambridge Univesity Press.

28. Block, N. (1995), On a confusion about a function of consciousness // Behavioral and Brain Sciences. Vol.18. №2. P.227-247.

29. Hameroff, S.R., Craddoc, T., Tuszynski, J.A. (2014) Quantum effects in the understanding of consciousness // Journal of Integrative Neuroscience. Vol.13. №2. P.229-252. 
30.Honderich, T. (2014) Actual Consciousness, UK, OXFORD University Press.Journal of Consciousness Studies. Special Issue: Integrated Information Theory // Edited by Garrett Mindt. Vol.26. №1-2. 2019.

31. Kriegel, U Intentionality // The Oxford companion to Consciousness. Edited by Tim Bayne, Axel Cleeremans, Patrik Wilken. 2009. OXFORD Univesity Press. Pp. 382385.

32. Levin, J. (1983) Materialism and Qualia: the Explanatory Gap // Pacific Philosophical Quartely. Vol.64. №4. P.354-361.

33. Morin, A Innner speech // // The Oxford companion to Consciousness. Edited by Tim Bayne, Axel Cleeremans, Patrik Wilken. 2009. OXFORD Univesity Press. Pp. 380382.

34. Nagel, T. (1974) What is it like to Be a Bat? // The Philosophical Reviev. Vol.83. №4. P.435-450.

35.Putnam, H. (1988) Representation and reality. Cambridge. Mass.: MIT Press.

36.Searle, J.R. (1997) The mystery consciousness. New York: New York Reviev Books.

37. Tononi, G. (2009) An integrated information theory of consciousness. In W.B. Banks (Ed), Encyclopedia of Consciousness (pp. 403-416). San Diego. CA: Academic Press.

38.Velmans, M. (2009) Understanding consciousness $\left(2^{\text {nd }}\right.$ ed) Hove: Rontledge.

\section{CATEGORICAL SPACES IN THE STATEMENTS AND SOLUTIONS OF THE PROBLEM OF CONSCIOUSNESS}

Akopov G.V. (Samara State University of Social Sciences and Education, Samara, Russia)

Substantial rethinking and expansion of terminological means for determining consciousness (qualia, subjectivity, access-consciousness, global workspace, etc.), as well as methodological foundations, approaches, and concepts allowed us to form a new field of interdisciplinary research in English-language sources ("Science of Consciousness»). The cultural and historical specificity of the development of scientific knowledge in various countries has led to certain differences in the terminological design of the problem of consciousness. Categories as fundamental concepts, together with interrelated concepts and terms, predetermine the formulation, approaches and conceptual solutions to the problem of consciousness. In this context, one can speak of various categorical "spaces» of the problem of consciousness. Categorical spaces of various theories of consciousness can be a tool not only for analyzing the integrity of a particular concept, but also for comparative as well as cross-cultural research.

Keywords: consciousness, category; problems of consciousness, different approaches, theories; sociocultural specificity; term, concept, categorical spaces. 